\title{
A conceptual classification of parents' attributions of the role of food advertising in children's diets
}

\author{
Simone Pettigrew ${ }^{1 *}$, Kathy Chapman², Caroline Miller ${ }^{3}$ and Samantha Thomas ${ }^{4}$
}

\begin{abstract}
Background: High levels of child obesity are triggering growing concerns about the prevalence and effects of food advertising targeted at children. Efforts to address this advertising are confounded by the expanding repertoire of media and promotional techniques used to reach and attract children. The present study explored parents' views on food marketing and the strategies parents employ when attempting to ameliorate its effects. As part of an online survey of Australian parents' attitudes towards a range of food advertisements, respondents were invited to provide additional comment in an open-ended question. The question was optional and asked "Are there any other comments you would like to make?". One in five of the survey respondents $(18 \% ; n=235)$ elected to answer this question by discussing their views on food advertising and children's diets. The responses were imported into NVivo10 for coding and analysis. A grounded approach was used to draw meaning from the data and develop a proposed conceptual classification of parents' attributions relating to food advertising and its consequences.

Results: The majority of responses related to the negative perceived effects of unhealthy food advertising on children's diets, with few respondents considering such advertisements to be innocuous. The responses were classified into four conceptual categories reflecting differing attitudes to advertising (negative to neutral) and varying levels of locus of control (low to high). The typical characteristics of parents allocated to the four categories exhibited variation according to weight status, television viewing habits, education level, and family size. The largest number of responses was coded to the category characterized by a negative attitude toward food advertising and a low locus of control. Parents in this category were more likely than others to be overweight/obese and heavy television viewers. Parents in the negative attitude to advertising and high locus of control category nominated a variety of parenting practices that could form the basis of parent education interventions.
\end{abstract}

Conclusions: The results suggest that many Australian parents may feel disempowered in the face of high levels of advertising for unhealthy foods. The current voluntary regulatory code appears to be inadequate in scope and coverage to address this situation.

Keywords: Parents, Children, Food advertising, Policy, Regulation

\section{Background}

In their Global Action Plan for the Prevention and Control of Noncommunicable Diseases, [1] the World Health Organization (WHO) recognizes the critical role of increasing obesity levels in contributing to high and growing global rates of noncommunicable diseases, including heart disease, cancer, and diabetes. The International Network for Food and Obesity/noncommunicable diseases Research, Monitoring and Action Support (INFORMAS)

\footnotetext{
* Correspondence: simone.pettigrew@curtin.edu.au

${ }^{1}$ School of Psychology and Speech Pathology, Curtin University, GPO Box U1987, Perth, WA 6845, Australia

Full list of author information is available at the end of the article
}

was recently established to guide efforts to implement and assess government policies relating to noncommunicable disease prevention [2]. Both the WHO's Global Action Plan and the INFORMAS framework [1-4] emphasize the importance of health-promoting environments in assisting individuals to make healthy choices. Similarly, the food environment is a major component of the World Cancer Research Fund's NOURISHING framework [5] that relates specifically to the food policy options available to governments seeking to address health issues through the food supply.

Children have been a primary target group for obesity prevention programs to date because of the difficulty 
associated with addressing obesity after onset and in adulthood and the tendency for obesity in childhood to track into adolescence and adulthood [6-8]. Key health organizations and independent experts consistently emphasize the need to address the marketing of unhealthy foods to children as part of the process of ensuring that children's environments are conducive to healthy food choices [9-13]. This emphasis reflects the outcomes of major reviews that have identified food advertising as a contributing factor to children's food preferences, choices, and diets [9,14-16].

Specifically, greater exposure to advertising for unhealthy foods and beverages is associated with higher body mass index (BMI) scores in children [17]. Substantial differences in rates of child obesity between countries have been partially attributable to food advertising contexts, with countries with higher levels of television food advertising tending to exhibit higher levels of child obesity [18]. Longitudinal data indicate that it is the exposure to food advertising rather than television viewing per se that contributes to the effect on BMI [19]. This conclusion is supported by recent work that has found that children with higher levels of awareness of fast food brands have higher BMI scores than their less-aware peers [20]. Novel research using magnetic resonance imaging techniques indicates that obese children exhibit reduced cognitive control responses when exposed to food logos relative to their normal weight peers [21]. The mechanisms via which food advertising influences children are thus complex and are likely to remain poorly understood for some time.

Despite the substantial and growing evidence base relating to the effects of food advertising on children, policy responses to this issue have been underwhelming [9]. To date, the main emphasis has been on television advertising $[22,23])$, but even in this area the number of countries implementing broad-ranging mandatory regulations has been relatively small. For example, in Australia, the context of the present study, advertising is prohibited during programs designed for pre-schoolers, but protection for older children (5-12 years) relies on voluntary regulations that apply to only a limited number of food company signatories, resulting in continued heavy exposure to advertisements for unhealthy foods [24,25]. A similar situation exists in the United States [26].

Developing and implementing effective policy responses has been complicated by the rapid expansion of food marketing into non-television media. Over the last decade, food companies have increasingly invested in alternative forms of promotion such as those involving digital media and the sponsorship of sports and events [11,27-30]. The recency of this phenomenon and the difficulties associated with monitoring and assessing the impacts of alternative media have resulted in a limited evidence base upon which to advance public policy relating to food marketing. However, the limited research to date suggests that these forms of food promotion can influence children's foodrelated beliefs and choices [31-33]. It is therefore critical that policies designed to protect children from food promotion include coverage of these elements [30].

Community support is an important consideration for governments contemplating the introduction or modification of health policies [34,35]. Research in Australia indicates strong levels of community support for stricter regulations relating to food marketing to children [36-38]. At the same time, however, there is substantial discourse around the roles and responsibilities of parents in providing healthy foods and modelling their consumption [38,39]. Various parenting styles and practices have been examined in terms of their likely impact on children's weight outcomes, with parents who are either too permissive or too authoritarian appearing to be more likely to have poorer child-feeding behaviors than parents who adopt a middleground 'authoritative' style [40,41].

It seems likely that a multi-faceted approach that includes public policy efforts to both curb the promotion of unhealthy foods and educate and encourage parents to improve their child-feeding practices is needed to address current high rates of child obesity. To optimize its effectiveness, such an approach requires an understanding of the extent to which different segments of parents attribute their children's weight outcomes to their own actions or those of external forces. Little is known about segment variation in terms of causal attributions, as many of the relevant studies to date have provided aggregated data relating to parents' attitudes to food marketing to children $[37,38,42]$, considered perceptions of causes of obesity in general rather than child obesity $[43,44]$, or focused on the food-related attitudes and behaviors of disadvantaged groups $[45,46]$. As outlined below, the present study utilized an exploratory approach to generate data about Australian parents' attributions regarding their children's diets and the role of food promotion, with a segmentation approach used to provide insight into the varying perspectives of different groups of parents.

\section{Method}

The data set was extracted from the results of a larger study that involved an online survey of 1,302 Australian parents of children aged 8 to 14 years. The purpose of the survey was to assess the effects of exposure to various forms of food advertising on attitudes to and desire for unhealthy foods. The study received ethics clearance from the University of Western Australia Human Research Ethics Committee.

A large web panel provider with access to a representative sample of Australians was used to source respondents with varying demographic profiles (see Table 1). After a 
series of questions relating to their general attitudes to unhealthy foods and beverages, one-third of the parents sampled were exposed to television advertisements for a selection of different unhealthy food products, one-third were exposed to six internet advertisements for the same foods, and one-third were shown small images of the same foods as the control condition. The foods included snacks, fast food meals, confectionery, and sodas. Respondents were asked various questions relating to their perceptions of the advertised products. The survey concluded with a series of demographic and behavioral questions, including the respondent's gender, age, postcode, television viewing patterns, and height and weight (for BMI calculation). The results indicated that both adults' and children's foodrelated preferences and social norms were influenced by

Table 1 Sample profile

\begin{tabular}{|c|c|c|c|}
\hline \multicolumn{2}{|c|}{ Respondent attributes* } & \multirow{2}{*}{$\begin{array}{l}\begin{array}{l}\text { Total sample } \\
(n=1302) \%\end{array} \\
67\end{array}$} & \multirow{2}{*}{$\begin{array}{l}\text { Qualitative data } \\
\text { sub-sample }(n=235) \% \\
75\end{array}$} \\
\hline Gender & Female & & \\
\hline & Male & 33 & 25 \\
\hline \multirow[t]{3}{*}{ Age } & $18-30$ & 5 & 6 \\
\hline & $31-39$ & 93 & 93 \\
\hline & $40+$ & 1 & 0 \\
\hline \multirow[t]{3}{*}{$\begin{array}{l}\text { Weight status } \\
\text { (BMI) }\end{array}$} & $\begin{array}{l}\text { Healthy } \\
\text { weight }\end{array}$ & 34 & 32 \\
\hline & Overweight & 24 & 27 \\
\hline & Obese & 18 & 18 \\
\hline \multirow{4}{*}{$\begin{array}{l}\text { No. of } \\
\text { children }\end{array}$} & 1 & 29 & 27 \\
\hline & 2 & 50 & 53 \\
\hline & 3 & 18 & 17 \\
\hline & 4 & 3 & 3 \\
\hline \multirow[t]{6}{*}{$\begin{array}{l}\text { Highest level } \\
\text { of education }\end{array}$} & $\begin{array}{l}\text { Incomplete } \\
\text { schooling }\end{array}$ & 3 & 1 \\
\hline & Year 10 & 10 & 9 \\
\hline & Year 12 & 17 & 17 \\
\hline & $\begin{array}{l}\text { Technical } \\
\text { qualification }\end{array}$ & 28 & 32 \\
\hline & $\begin{array}{l}\text { Undergraduate } \\
\text { degree }\end{array}$ & 25 & 26 \\
\hline & $\begin{array}{l}\text { Postgraduate } \\
\text { degree }\end{array}$ & 17 & 14 \\
\hline \multirow{2}{*}{$\begin{array}{l}\text { Family } \\
\text { structure }\end{array}$} & Single parent & 15 & 14 \\
\hline & Two parents & 80 & 81 \\
\hline \multirow[t]{3}{*}{ TV viewing } & $\begin{array}{l}\text { Low (<15 } \\
\text { hours/week) }\end{array}$ & 8 & 10 \\
\hline & $\begin{array}{l}\text { Medium (15-28 } \\
\text { hours/week) }\end{array}$ & 56 & 57 \\
\hline & $\begin{array}{l}\text { High (29+ } \\
\text { hours/week) }\end{array}$ & 35 & 32 \\
\hline
\end{tabular}

*Missing values not reported. food advertising, despite current food advertising regulations being based on assumptions of adult immunity to advertising effects [32].

Towards the end of the online questionnaire, respondents were given the opportunity to provide additional input via an open-ended question: "Are there any other comments you would like to make?" Respondents could comment on the content or structure of the survey, or any other issue they felt to be relevant or of interest. A small number $(n=39)$ commented on the survey, most of whom noted that they had enjoyed taking part in the study. A further 235 parents (18\% of respondents) took the opportunity to make comments relating to their perceptions of the influence of food advertising on their children's diets. The primary focus of these comments on food advertising reflected the emphasis on this issue in the main body of the survey instrument. Table 1 provides a comparison of the demographic profiles of the entire sample and the 235 parents providing additional comment. The only notable difference between the two groups was gender: women constituted two-thirds of the total sample, but accounted for three-quarters of those providing optional comments.

The qualitative data and accompanying demographic details were imported into NVivo10 for coding and analysis. In accordance with the procedures and principles of a grounded approach to data analysis [47], the intention was to produce a thematic analysis that incorporated the similarities and differences identified in the data. This involved the inductive development of a coding hierarchy that included nodes relating to the demographic, attitudinal, and behavioral variables evident in the data. An initial reading of the comments preceded numerous coding sweeps to achieve the various stages of open, axial, and selective coding [48]. NVivo's matrix query function was then used to interrogate the coded data to identify the characteristics of clusters of parents who shared common attitudes and concerns.

Due to the use of an emergent coding process rather than a pre-established coding framework, a single coder (the first author) undertook all coding to maximize the consistency of coding to the broad and emergent range of nodes. The findings were subsequently discussed among the members of the research group to refine the resulting analysis and consider the outcomes in the light of existing evidence in this domain. This process involved discussing various alternative interpretations of the data and agreeing on the primary outcomes of interest and how they could be most parsimoniously combined into conceptual categories. This resulted in a thematic interpretation that produced the two primary themes of negative advertising attributions and perceived locus of control. These themes and their interactions are discussed below. 


\section{Results}

Although the survey included questions about food advertising across multiple media, respondents referring to advertising in their responses to the optional openended question focused almost exclusively on television advertising. There were no differences in this emphasis between the three conditions (exposure to television advertisements, internet advertisements, or control pictures). Many of the comments were in the form of suggested strategies for either dealing specifically with the effects of television advertising for unhealthy foods or for generally managing children's diets and health. As shown in Table 2, the two primary themes that were identified across the comments and suggested strategies were advertising attributions and locus of control.

Advertising attributions ranged from neutral to negative. Positive comments about the effects of advertising were virtually absent, although one respondent expressed the desire to receive more discount coupons from fast food restaurants. Neutral comments typically referred to ways in which food advertising could be potentially more constructive or provided reasons why advertising effects were perceived to be minimal. Negative comments appeared to be founded on the view that advertising for unhealthy foods is highly effective in triggering and reinforcing children's preferences for unhealthy foods. As such, the strategies suggested by respondents with this perspective constituted means of either avoiding exposure to advertisements or managing the effects of exposure, including subsequent instances of pestering.

Locus of control refers to the extent to which individuals attribute outcomes to their own efforts or other forces [49,50]. A high locus of control is evident where individuals consider themselves to have substantial control over outcomes, and a low locus of control occurs where individuals perceive themselves to have minimal control. The locus of control dimension exhibited by the study respondents ranged from low to high. Parents exhibiting a low locus of control favored policy-level initiatives to curb or modify the advertising of unhealthy foods. Those parents whose responses indicated a high locus of control often mentioned a range of behaviors parents can enact to prevent children's diets and health from being unduly affected by food advertising. The way in which locus of control was manifest in the responses included direct reference to parents' ability to control exposure to and effects of food advertising, as well as control over their children's diets more generally.

The sections to follow outline the primary findings relating to the four combinations of advertising attributions and locus of control. Table 2 shows how these two major themes intersect to represent a proposed conceptual classification of parents' attributions of the role of food advertising in children's diets. The quadrant representing the largest number of responses is Quadrant 4 (negative advertising effects, low locus of control). Around four in ten of the comments were allocated to this quadrant and around one-third of the responses were aligned with Quadrant 1 (negative advertising effects, high locus of control). Most of the strategies mentioned by the respondents thus mapped on to the lefthand-side of Table 2, reflecting an overall general perception among the parents that food advertising is a negative influence on their children.

Table 2 Parents' perceptions of appropriate responses to unhealthy food advertising

\begin{tabular}{|c|c|c|c|}
\hline \multicolumn{4}{|c|}{ High locus of control } \\
\hline & Quadrant 1: Parents need to exert control (35\%) & Quadrant 2: Everything is okay (13\%) & \\
\hline & - Watch commercial-free TV channels & - Everything in moderation & \\
\hline & - Change channels during ad breaks & - Unhealthy foods used for treating & \\
\hline & - Just say no & $\begin{array}{l}\text { - Physical activity can counteract unhealthy food } \\
\text { consumption }\end{array}$ & \\
\hline & - Avoid using food as a reward & & \\
\hline & - Model healthy eating behaviors & & \\
\hline \multirow{7}{*}{$\begin{array}{l}\text { Advertising } \\
\text { as negative }\end{array}$} & - Teach children to understand the purpose of advertising & & \multirow{7}{*}{$\begin{array}{l}\text { Advertising } \\
\text { as neutral }\end{array}$} \\
\hline & $\begin{array}{l}\text { Profile: Normal weight parents with lower levels of } \\
\text { television viewing }\end{array}$ & Profile: Females of normal weight with one child & \\
\hline & Quadrant 4: Something should be done (43\%) & Quadrant 3: Ambivalence (9\%) & \\
\hline & - Ban advertisements & - More advertisements for healthy foods & \\
\hline & - Control content of advertisements & - Better advertisements for healthy foods & \\
\hline & - Control timing of advertisements & - The power of peers & \\
\hline & $\begin{array}{l}\text { Profile: Overweight or obese parents who are heavy } \\
\text { television viewers }\end{array}$ & $\begin{array}{l}\text { Profile: Overweight parents with lower education levels and } \\
2+\text { children }\end{array}$ & \\
\hline \multicolumn{4}{|c|}{ Low locus of control } \\
\hline
\end{tabular}


In the discussion of each quadrant below, the profiles of parents whose responses were most closely aligned with the quadrant are outlined. Descriptors are provided with the respondent extracts, although not all attributes (particularly their height and weight) were reported by all respondents and hence some details are absent (primarily BMI). Abbreviations are used in the descriptors for gender (M, F), weight status (healthy weight $(\mathrm{HW})$, overweight $(\mathrm{OW})$, obese (OB)), number of children (1C, 2C, 3C, 4C), education (low (LowEd), medium (MedEd), high (HighEd)), and television viewing level (LowTV, MedTV, HighTV). Minor typographical and grammatical modifications were made to some extracts to improve readability.

\section{Quadrant 1: high locus of control, negative advertising effects}

Comments allocated to this quadrant included suggestions for how parents can actively manage their children and their households to overcome the negative effects of food advertising. These suggestions appeared to be based on the assumptions that food advertising is an adverse force and that an important aspect of the parental role is to purposively work against this force. This parental work involved minimizing children's exposure to food advertisements and/or providing them with guidance post-exposure to address any adverse effects.

Parenting strategies that were nominated as being useful for avoiding children's exposure to food advertising primarily involved monitoring and controlling children's television viewing in the home. As noted above, there was virtually no acknowledgement that children can be exposed to promotional messages for unhealthy foods via media other than television. As such, most recommendations relating to advertising exposure were focused on three actions: only permitting children to watch commercial-free television stations, changing channels during the ad breaks, or limiting exposure to television altogether:

We try to let them only watch commercial-free television, especially in the morning because of the plethora of unethical advertising directed at them! (F, 3C, HW, MedEd, MedTV)

I do not let my child watch much commercial TV so she isn't bombarded by advertising. (F, 2C, LowEd, MedTV)

I try to change the channel when the ads are on. (M, 1C, OB, LowEd, MedTV)

For TV ads, limiting viewing time is ideal but difficult. (F, 2C, HW, MedEd, MedTV)

Similarly, strategies for overcoming negative effects of food advertising after exposure typically involved ways of interacting with children in the home environment to redress the effects of advertising. The most common suggestion was to adopt a 'just say no' approach. Using parents' authority to overcome children's requests for unhealthy foods that follow exposure to food advertisements was seen to be both a right and a duty:

It is always up to the parent - no matter what advertising the child sees. (M, 3C, OW, HighEd, HighTV)

The child's requests may be based on ads they see, however it is up to the parent to decide whether or not to allow them to have the requested food. (F, 2C, HighEd, MedTV)

Kids are impressionable but the PARENTS make the choices, and shouldn't blame products or advertising when they make poor ones because it's easier and/or they want their children to like them. (F, 2C, OW, LowTV)

Children's food choices and eating habits can be influenced by TV ads, but it's up to their parents to make sure they are eating healthily and not overly influenced by these ads. (F, 2C, HW, MedEd, MedTV)

Ultimately it is the parent who has the choice. If they don't think the food is good, don't give it to them. If an ad comes on TV for it, the parent CAN say NO.

$(M, 1 C, M e d E d, M e d T V)$

Being consistent in refusing to purchase the advertised foods was seen by some parents to be effective in preventing future requests because children come to see pestering as an unproductive use of their time and effort:

$T V$ advertising only influences if it's then followed up with purchase by parents. If parents don't give in, the kids don't ask and write it off out of their minds on all future advertising. (F, 1C, HighEd, MedTV)

In addition to controlling television viewing and persistently refusing requests, a further suggested parental strategy was to avoid the use of unhealthy foods as a reward, thereby minimizing the emotional use of food. Instead, the recommendation for teaching children about food and eating was to focus on the role of food in nourishing the body:

If you instil in your child from an early age that food is sustenance and not to associate it with rewards, there would be a lot less obesity, anorexia, bulimia etc. (F, 2C, OW, MedEd, MedTV)

I have taught my children the difference between good and bad foods. I never give food as a treat and never 
associate food with rewards. This could cause emotional eating. My children eat because it's fuel. (F, 2C, MedEd, MedTV)

A fourth suggested approach was to model healthy eating behaviors in front of children to demonstrate the normality of healthy foods and how they can be enjoyed and appreciated:

In the end, it's my choice and responsibility to give my children a healthy, balanced diet. In the end, what I put in my mouth has more influence in what my kids eat. (M, 3C, OW, HighEd, HighTV).

I think its important parents set a good example of eating healthy food choices and persisting with their children that they also eat good healthy foods.

(M, 1C, HW, HighEd, MedTV)

Whilst children are influenced in their eating habits by what their friends eat and by advertising, a good example and teaching of healthy eating habits at home can exert the major influence. (F, 3C, OW, HighEd, LowTV)

The final recommendation relating to parents' interactions with their children was the provision of information about the purpose and nature of advertising. Some parents appeared to be of the view that this information can adequately arm children to prevent them being unduly influenced by advertising, although others perceived it to be an ongoing battle:

I have taught my son to look through the advertising and propaganda and look at the actual product. (F, 1C, OW, MedEd, MedTV)

It's parental obligation to explain what the aim of the ad is. (F, 2C, HighEd, MedTV)

\section{I believe that most children are influenced by} advertising, but my children have been explained the purpose of advertising and know what is good for them and what is not. They only want to eat things that are healthy for them and occasionally want treats. (F, 2C, HW, HighEd, MedTV)

Telling my child why the ad is misleading or why the choice is not good makes her a better informed consumer, although she still wants it more than I will provide it. (F, 2C, OB, HighEd, MedTV)

Compared to all parents providing comments and the total sample, the responses that were aligned with
Quadrant 1 were more likely to originate from parents of normal weight and who reported spending fewer hours watching television. Given their own weight status, these parents may be coping better with managing the food supply in the home relative to other respondents. The lower levels of exposure to television reflect some of the strategies discussed (e.g., limiting/managing exposure to advertisements) and assist the implementation of others (e.g., they may have to 'just say no' less frequently because the television is not on in the house as much, thereby reducing children's exposure to food advertisements).

\section{Quadrant 2: high locus of control, neutral advertising effects}

As shown in Table 2, there were considerably fewer responses aligned with those quadrants characterized by neutral perceptions of food advertising. Comments assigned to Quadrants 2 and 3 tended to be shorter in length and therefore less expansive on the issues raised. They were also less likely to be as emotive in nature as the comments that were aligned with Quadrants 1 and 4 .

The comments that fit best into Quadrant 2 were those that indicated a belief that food advertising has relatively minor effects on children, and that these effects can be easily addressed through normal parenting practices that relate to factors other than food advertising. These practices included providing a balanced diet, engaging in occasional treating behaviors, and ensuring children are physically active.

The idea of moderation to achieve a balanced diet was a particularly strong theme within the responses assigned to this quadrant. The term was used as being self-explanatory, without the provision of information about what constitutes a moderate intake of unhealthy foods:

Everything in moderation! (F, 1C, HW, LowEd, MedTV)

Fast food or treats in moderation are fine, provided it is part of an overall good diet. (M, 1C, OB, HighEd, MedTV)

As indicated in the quote above, some of the parents noted that food treating is an important aspect of the parent-child relationship, and thus these kinds of foods have a valid role to play in a balanced diet:

I feel that we have a very healthy diet, so the occasional treat is OK and necessary. (F, 2C, MedEd, HighTV)

Often parents like to treat their children with these things for good work, sportsmanship and behavior. (F, 1C, HW, MedEd, HighTV) 
I believe treats are good in moderation and it depends on how healthy a diet the child has in general. Ideally he wouldn't eat anything bad for him, but realistically he has to live and enjoy life. Everything in moderation is my motto. (F, 1C, HW, HighEd, HighTV)

An aspect of the moderation theme was the belief that as long as children are physically active, the consumption of high-energy foods is unproblematic:

There is nothing wrong with active children having lollies (candy), soft drink (soda), fast food etc. in moderation. (F, 2C, MedEd, MedTV)

The overall sense was that food advertising was not considered problematic by these parents because they believed their children's intake of unhealthy foods was appropriate regardless of their exposure to advertisements and without effortful parental intervention. Among those expressing this view, females, those of normal weight, and those with just one child were disproportionately represented. It may be that having only one child made parents more amenable to treating and simplified the provision of physical activity opportunities. Alternatively, these may be younger families and the development of the child and/or later arrival of siblings may serve to make the problems associated with providing a balanced diet more salient.

Quadrant 3: low locus of control, neutral advertising effects Reflecting the low locus of control characterized by Quadrants 3 and 4, respondents aligned with these quadrants appeared to attribute their children's food preferences to factors outside the home, and hence they reported a desire for changes in the management of food advertising at a community (rather than household) level. They looked to external parties to take action because they felt powerless as individuals to make a meaningful difference. The comments attributed to Quadrant 3 were smaller in number and tended to focus on either the possibility of using food advertising as a positive force or the attribution of children's pestering to external factors other than advertising.

Most of the comments allocated to Quadrant 3 focused on the potential for other food producers or government agencies to also use television advertising to increase demand for healthy products. These respondents felt that a greater number of advertisements for healthy foods and more creative advertisements for these foods could tap into the ability of advertising to influence children's behavior in a positive way. They thus exhibited a degree of ambivalence in their recognition of the potential for food advertising to constitute both a positive and negative force on their children's diets. There did not appear to be any recognition of the very high costs associated with television advertising and therefore the difficulties associated with using this medium for smaller producers or those with lower profit margins.

I wish more healthy ads were available for my child to see more often. (M, 3C, LowEd, HighTV)

Far too many fast food ads on $T V$, not enough fresh food ads encouraging healthy lifestyles. (F, 4C, OW, LowEd, HighTV)

I would like to see veggies advertised looking as fun as junk food does. (F, 3C, MedEd, MedTV)

When looking beyond advertising to other external factors, some parents expressed the view that their children's peers were at least as influential as advertising in determining their children's food preferences, if not more so. They thus perceived advertising to be less problematic than parents who viewed the advertising of unhealthy foods as being the dominant factor confounding their attempts to provide their children with a healthy diet. Of note was that parents referring to peers seemed to consider advertising and peers to be completely separate issues, thereby failing to appreciate that peers are also likely to be influenced by advertising:

Peer pressure creates a huge demand on parents to buy the most popular treats/snacks or visit fast food outlets. My guess would be that 75\% of the items my children request they have become aware of because someone else has it in their school lunch. (F, 2C, OB, MedEd, MedTV)

I believe children are influenced by their peers in food habits and what tastes good. (F, 2C, OW, HighTV)

There's advertising, but also at school they are indoctrinated into the McDonald's way. (F, 2C, $O B$, MedEd, MedTV)

Differentiating attributes of parents whose comments were allocated to this quadrant were having a larger number of children, being overweight, and a lower level of education. Relative to other respondents, these parents may have fewer resources available to cope with child pestering and may be less aware of the potential for policy-level initiatives to assist with controlling levels of advertising for unhealthy foods.

\section{Quadrant 4: low locus of control, negative advertising effects} There were more comments indicating a low locus of control in combination with negative attributions about advertising than any other combination of these factors. This reflected an overwhelming tendency to view 
advertising for unhealthy foods as a negative force to be reckoned with, in addition to a desire for societal-level modifications to the advertising environment. The following extracts demonstrate the intensity of feeling that was evident in some of the responses:

It annoys me that big profits are put ahead of children's health. (F, 3C, LowEd, HighTV)

\section{I hate the advertising aimed at kids!!! (M, 2C, OW, HighEd, MedTV)}

These concerns appeared to be derived from a perception of substantial adverse effects of such advertisements on their children:

My 8 year old child has a basic knowledge about healthy eating and Red, Yellow, Green foods. However she has no discernment when it comes to $T V$ advertising, what she sees/hears in an ad is taken as gospel truth. Therefore it has a strong influence on her. (F, 2C, OB, HighEd, HighTV)

I hate all the advertising directed at children, it is the main reason our kids are so unhealthy. Even when we refuse to buy our kids these unhealthy snacks, they will get their hands on them one way or the other.

(F, 3C, LowEd, HighTV)

Promotional efforts by fast food restaurant chains, especially those including toys to incentivize food purchase, were considered to be particularly insidious:

My child will often ask for particular fast foods because they come with a toy, even though he actually enjoys other food more. That really annoys me. (F, OW, HighEd, HighTV)

Fast food advertising has grown in the area of children's treats. Now most outlets offer a children's menu with a toy or gift, so it makes it hard to offer a healthier option if these are in their face. (F, 2C, HW, MedEd, HighTV)

I wish they wouldn't have toys at McDonald's as it attracts the kids to eat bad food. (M, 2C, HW, HighEd, LowTV)

Several different but related suggestions for appropriate methods of addressing the problem of unhealthy food advertising at the policy level were nominated. The first involved requiring food companies to provide more complete and 'honest' information in their advertisements:
I wish that the ads would include the nutritional value or lack of. These kids need to know exactly what they are eating. They are not as stupid or as dumb as you think! (F, 2C, OW, MedEd, MedTV)

The second suggestion was for the sheer quantity of advertisements to be addressed to reduce the level of exposure among both children and their parents:

Some ads should be banned from children's programs as some children and their parents are impressionable. This is leading to obesity in childhood for sure. (F, 2C, HW, HighEd, MedTV)

There are too many ads in children's $T V$ time slots, which coincidently is usually the busiest time for parents. (F, 1C, OB, MedEd, MedTV)

Third, and as alluded to in the comment above, some respondents wanted mandatory regulations introduced to prevent unhealthy foods from being promoted during children's peak viewing times:

Fast food ads should be banned from prime time $T V$. (M, 1C, MedEd, MedTV)

Children should not be targeted during their shows with lollies (candy) and fast food, especially since these programs run just before dinner time. (M, 2C, OB, MedEd, MedTV)

These ads should not be allowed during children's viewing time. (M, 2 children, obese, MedEd, HighTV)

Fast food advertisements should be BANNED on children's television! (M, 2C, OW, MedEd, MedTV)

Fourth, there were also calls for the complete banning of advertisements for unhealthy foods, regardless of time of screening:

We would like to see junk food advertising limited by Government, even banned entirely. (M, 2C, OW, HighEd, LowTV)

\section{Fast food ads should be banned. (F, 1C, HighEd, MedTV)}

In terms of respondent attributes, those parents making comments aligned with this quadrant were more likely than others to be overweight or obese and to be heavy television viewers. This group of parents may experience particular problems ensuring that their family consumes a healthy diet, as evidenced by their own weight status. Their 
extensive television viewing may make them more vulnerable to the repetition effects of advertising that can result in greater preference and choice simply through repeated exposure [51].

\section{Discussion and conclusions}

One in five respondents took additional time when completing an already lengthy survey to provide specific input relating to their views on the nature of food advertising and how it could or should be addressed. The opt-in nature of the open-ended question and the tendency for the large majority of those electing to respond to this question to discuss issues relating to food advertising indicate that the topic was of considerable interest to these parents. The high proportion of women choosing to add further comment is consistent with previous research demonstrating that women are generally more willing than men to participate in research [52].

A key finding of the study was an apparent lack of awareness of forms of food promotion targeting children other than television advertising. This outcome is in line with the continuing dominance of television in companies' food advertising repertoire [10], and is consistent with previous research [36], but is a cause for concern given the extent to which unhealthy foods are now promoted to children via numerous other methods [27-29]. Other forms of food promotion thus need to be made salient to parents so they can be aware of possible effects and make informed decisions about their children's exposure [53]. In addition, parents have been identified as a key stakeholder group that can exert pressure on governments to introduce policies that have the potential to improve children's health [26]. A lack of awareness of the extent and effectiveness of other forms of marketing prevents parents from contributing to public discussions of these issues and hence reduces their ability to influence outcomes.

A second major finding was that parents' views on the effects of food advertising may vary according to their personal characteristics. In particular, it seemed that those respondents who were overweight or obese and spent more time watching television were more likely to express views that indicated a low locus of control relating to the influence of advertising on their children. The relationship between amount of television exposure and diet quality and obesity has been well-established [54,55], with potential causes including higher levels of sedentary activity and greater exposure to advertising for unhealthy foods among those watching more television [54]. The present study adds to these previous results by providing insight into the views of overweight parents who are heavy television viewers. As demonstrated by Quadrant 4, these parents may feel unable to cope with the competing pressures, including food advertising, that adversely affect their ability to ensure that their children (and they themselves) consume a healthy diet.

This finding is of concern given that the majority (62\%) of Australian adults are overweight or obese [56] and the average time spent viewing television is 13 hours per week [57]. A substantial proportion of the population is therefore likely to possess the attributes associated with the low locus of control that is characteristic of Quadrant 4. This situation would appear to support the need for greater regulatory oversight of food advertising to protect the interests of families where parents experience difficulties managing their children's exposure to high levels of such advertising and may not be aware of methods to counteract the effects of exposure once it has occurred. The current regulatory approach in Australia (a voluntary system that applies to a limited number of food company signatories) is based on assumptions of parents' own immunity to food advertising, their ability to mediate their children's exposure to advertising, and their ability to educate their children about how advertising works. The findings of the present study support those of other recent work that demonstrates that these assumptions are unfounded [32,58], and hence highlight the need to provide appropriate policy-level support for parents. As recently noted by the Director General of WHO [59], "Not one single country has managed to turn around its obesity epidemic in all age groups. This is not a failure of individual will-power. This is a failure of political will to take on big business." This process of "taking on big business" would involve recognizing the role of the food industry practices in contributing to the obesity epidemic and the need for mandatory rather than voluntary regulation of food advertising and other forms of food promotion [60].

Parents' whose comments were represented in Quadrant 1 interpreted food advertising as a negative force, but appeared to have internalized a personal responsibility script that caused them to attribute accountability for redressing the situation to themselves. This prevented them from identifying a need for community-level responses. They also seemed to lack an appreciation of the effects of food advertising on the social norms that influence the broader social environments in which their children are immersed [10].

On a more constructive note, the behaviors described in comments allocated to Quadrant 1 may constitute a form of 'positive deviance' that could form the basis of future parent education interventions that complement broader regulatory approaches. Positive deviance occurs where some individuals (or organizations) are able to adapt to changing circumstances in ways that are more effective than those employed by their peers [61]. By observing these adaptive behaviors and promoting them to the broader community, there is the potential to improve outcomes at the population level [62]. The 
strategies nominated by parents in Quadrant 1 are largely reflected in the child-feeding recommendations in the nutrition literature [63], and hence are likely to constitute a suite of behaviors that are appropriate for inclusion in parent education interventions. Developing interventions according to the 'real-world' experiences of parents through the positive deviance approach may serve to enhance the veracity and utility of the guidance provided. However, such interventions in isolation are unlikely to redress the negative consequences of pervasive advertising for unhealthy foods, and greater regulatory restrictions appear needed to reduce children's overall exposure [61]. As such, efforts may be needed to encourage a further form of positive deviance that involves parents actively seeking more extensive policy action in this area.

There is some support in the literature for Quadrant 3 respondents' hope in the potential of healthy food advertising to counteract the effects of advertising for unhealthy foods $[10,64,65]$. For example, a relationship has been found between children's exposure to advertisements for fruit and vegetables and their consumption of these foods [65]. However, there is a vast disparity in current levels of unhealthy food advertising relative to healthy food advertising [25], which suggests that the scale of investment required to off-set current levels of unhealthy food promotion is likely to be insurmountable for governments and producers of healthy foods.

A limitation of the present study is the reliance on qualitative data from an open-ended question in a quantitative survey. In addition, the content of the preceding items in the survey relating specifically to food advertising are likely to have primed the qualitative responses to the open-ended question. The $18 \%$ response rate for this particular question presents the possibility that the respondents are unrepresentative of the larger sample. However, the similarity in sample profiles, with the exception of gender, and the large sample for a qualitative study provide some assurance of the integrity of the data. In addition, the optional nature of the question and respondents' ability to raise any issues they perceived to be of interest or concern allowed topics to be raised more spontaneously than typically occurs in other data collection contexts. This approach facilitated the identification of two primary themes and four resulting classifications of parents according to their attitudes to food advertising, their perceptions of their level of control over the effects of food advertising, and their personal characteristics. This proposed classification suggests the need for a multi-faceted policy approach that includes both population-level strategies in the form of effective advertising regulation and family-level strategies that assist parents to implement practices in their homes to limit their children's exposure to food advertising and to ameliorate the effects of any exposure that does occur. Future research could seek to assess the extent to which the segments identified in this research are evident in the broader community. Work could also be undertaken to provide an evidence base for the kinds of positive deviance strategies that can be used effectively by parents in an attempt to at least partially ameliorate the effects of pervasive advertising of unhealthy foods in the absence of effective regulation to reduce children's exposure.

\section{Competing interests}

The authors declare that they have no competing interests.

\section{Authors' contributions}

SP conceptualized the study in conjunction with $\mathrm{KC}$ and $\mathrm{CM}$, managed data collection, coded the data, and took the lead in paper-writing. KC, CM, and ST assisted in data analysis and contributed to the writing of the paper. All authors read and approved the final manuscript.

\section{Acknowledgements}

The study was funded by an ARC Linkage grant (LP0991615) and co-funded by Cancer Council NSW and Cancer Council SA.

\section{Author details}

'School of Psychology and Speech Pathology, Curtin University, GPO Box U1987, Perth, WA 6845, Australia. ${ }^{2}$ Cancer Programs Division, Cancer Council NSW, 153 Dowling Street, Woolloomooloo, NSW 2011, Australia. ${ }^{3}$ Population Health Research Group, South Australian Health \& Medical Research Institute and School of Population Health, University of Adelaide, PO Box 11060, Adelaide, SA 5001, Australia. ${ }^{4}$ School of Health and Society, Faculty of Social Sciences and Australian Health Services Research Institute, Faculty of Business, University of Wollongong, Wollongong, NSW 2522, Australia.

Received: 19 April 2014 Accepted: 5 August 2014

Published: 15 August 2014

\section{References}

1. World Health Organization: Global Action Plan for the Prevention and Control of Noncommunicable Diseases 2013-2020. Geneva: WHO; 2013. Available http://www.who.int/nmh/publications/ncd-action-plan/en.

2. Swinburn B, Sacks G, Vandevijvere S, Kumanyika S, Lobstein T, Neal B, Barquera S, Friel S, Hawkes C, Kelly B, L'Abbé M, Lee A, Ma J, Macmullan J, Mohan S, Monteiro C, Rayner M, Sanders D, Snowdon W, Walker C for INFORMAS: INFORMAS (International Network for Food and Obesity/noncommunicable diseases Research, Monitoring and Action Support): overview and key principles. Obes Rev 2013, 14(S1):1-12.

3. Kumanyika S: INFORMAS (International Network for Food and Obesity/ non-communicable diseases Research, Monitoring and Action Support): summary and future directions. Obes Rev 2013, 14(S1):157-164.

4. Ni Mhurchu C, Vandevijvere S, Waterlander W, Thornton LE, Kelly B, Cameron AJ, Snowdon W, Swinburn B for INFORMAS: Monitoring the availability of healthy and unhealthy foods and non-alcoholic beverages in community and consumer retail food environments globally. Obes Rev 2013, 14(S1):108-119.

5. Hawkes C, Jewell J, Allen K: A food policy package for healthy diets and the prevention of obesity and diet-related non-communicable diseases: the NOURISHING framework. Obes Rev 2013, 14(S2):159-168.

6. Glavin K, Roelants M, Strand BH, Júlíusson PB, Lie KK, Helseth S, Hovengen R: Important periods of weight development in childhood: a populationbased longitudinal study. BMC Public Health 2014, 14:160. doi:10.1186/14712458-14-160.

7. Katan MB: Weight-loss diets for the prevention and treatment of obesity. New Eng J Med 2009, 360:923-925.

8. Magarey AM, Daniels LA, Boulton TJ: Predicting obesity in early adulthood from childhood and parental obesity. Int J Obesity 2003, 2003(27):505-513.

9. Cairns G, Angus K, Hastings G, Caraher M: Systematic reviews of the evidence on the nature, extent and effects of food marketing to children. A retrospective summary. Appetite 2013, 62:209-215. 
10. Harris $J \mathrm{~L}$, Brownell KD, Bargh JA: The Food Marketing Defense Model: integrating psychological research to protect youth and inform public policy. Soc Issues Pol Rev 2009, 3(1):211-271.

11. National Preventative Health Taskforce: Australia: The Healthiest Country by 2020. Canberra: Commonwealth of Australia; 2009.

12. World Health Organization: Marketing of Food and Non-alcoholic Beverages to Children. Oslo, Norway: World Health Organization; 2006. Available http:// www.who.int/dietphysicalactivity/publications/Oslo\%20meeting\%20layout\% 2027\%20NOVEMBER.pdf.

13. Zimmerman FJ: Using marketing muscle to sell fat: the rise of obesity in the modern economy. Annu Rev Publ Health 2011, 32:285-306.

14. Boyland EJ, Halford JCG: Television advertising and branding. Effects on eating behaviour and food preferences in children. Appetite 2013, 62:236-241.

15. Cairns G, Angus K, Hastings G: The Extent, Nature and Effects of Food Promotion to Children: A Review of the Evidence to December 2008. Geneva: World Health Organization; 2009. http://www.who.int/dietphysicalactivity/ Evidence_Update_2009.pdf

16. Hastings G, McDermott L, Angus K, Stead M, Thomson S: The Extent, Nature and Effects of Food Promotion to Children: A Review of the Evidence. Technical Paper Prepared for the World Health Organization. WHO; 2006. http://www. who.int/dietphysicalactivity/publications/Hastings_paper_marketing.pdf.

17. Andreyeva T, Rashad Kelly IR, Harris JL: Exposure to food advertising on television: associations with children's fast food and soft drink consumption and obesity. Econ Hum Biol 2011, 9:221-233.

18. Goris JM, Petersen S, Stamatakis E, Veerman JL: Television food advertising and the prevalence of childhood overweight and obesity: a multicountry comparison. Public Health Nutr 2009, 13:1003-1012.

19. Zimmerman FJ, Bell JF: Associations of television content type and obesity in children. Am J Public Health 2010, 100:334-340.

20. Cornwell TB, McAlister AR, Polmear-Swendris N: Children's knowledge of packaged and fast food brands and their BMI: hy the relationship matters for policy makers. Appetite 2014, doi:10.1016/j.appet.2014.06.017.

21. Bruce AS, Lepping RJ, Bruce JM, Cherry JB, Martin LE, Davis AM, Brooks WM, Savage CR: Brain responses to food logos in obese and healthy weight children. J Pediatr 2013, 2013(162):759-764.

22. Chapman K, Kelly B, King L: Using a research framework to identify knowledge gaps in research on food marketing to children in Australia. Aust N Z J Publ Heal 2009, 33:253-257.

23. Hawkes $C$, Lobstein T, Polmark Consortium: Regulating the commercia promotion of food to children: a survey of actions worldwide. Int J Pediatr Obes 2011, 6:83-94.

24. Hebden LA, King L, Grunseit A, Kelly B, Chapman K: Advertising of fast food to children on Australian television: the impact of industry self-regulation. Med J Aust 2011, 195:20-24

25. Roberts M, Pettigrew S, Chapman K, Miller C, Quester P: Compliance with children's television food advertising regulations in Australia. BMC Public Health 2012, 12. doi:10.1186/1471-2458-12-846

26. Harris JL, Sarda V, Schwartz MB, Brownell KD: Redefining "child-directed advertising" to reduce unhealthy television food advertising. Am J Prev Med 2013, 44(4):358-364

27. Cheyne AD, Dorfman L, Bukofzer E, Harris JL: Marketing sugary cereals to children in the digital age: a content analysis of 17 child-targeted websites. J Health Commun 2013, 18:563-582.

28. Montgomery KC, Chester J, Grier SA, Dorfman L: The new threat of digital marketing. Pediatric Clin North Am 2012, 59:659-675.

29. Pettigrew S, Rosenberg M, Ferguson R, Houghton S, Wood L: Game on: are children absorbing sports sponsorship messages? Public Health Nutr 2013, 16(12):2197-2204. doi:10.1017/S1368980012005435.

30. Story M, French S: Food advertising and marketing directed at children and adolescents in the US. Int J Behav Nutr Phy 2004, 1:3.

31. Harris JL, Speers SE, Schwartz MB, Brownell KD: US food company branded advergames on the internet: children's exposure and effects on snack consumption. J Child Media 2012, 6(1):51-68.

32. Pettigrew S, Tarabashkina L, Roberts M, Quester P, Chapman K, Miller C: The effects of television and internet food advertising on parents and children. Public Health Nutr 2013, 16(12):2205-2212.

33. Kelly B, Baur LA, Bauman AE, King L, Chapman K, Smith BJ: Food company sponsors are kind, generous and cool": (mis)conceptions of junior sports players. Int J Behav Nutr Phy 2011, 8:95.
34. Dodson EA, Fleming C, Boehmer TK, Haire-Joshu D, Luke DA, Brownson RC Preventing childhood obesity through state policy: qualitative assessment of enablers and barriers. J Public Health Pol 2009, 30:S161-S176.

35. Wong G, Pawson R, Owen L: Policy guidance on threats to legislative interventions in public health: a realist synthesis. BMC Public Health 2011, 11:222-232.

36. Kelly B, Chapman K, Hardy L, King L, Farrell L: Parental awareness and attitudes of food marketing to children: a community attitudes survey of parents in New South Wales, Australia. J Paediatr Child H 2009, 45(9):493-497.

37. Kelly B, Baur LA, Bauman AE, King L, Chapman K, Smith BJ: Views of children and parents on limiting unhealthy food, drink and alcohol sponsorship of elite and children's sports. Public Health Nutr 2013, 16(1):130-135.

38. Pettigrew S, Pescud M, Rosenberg M, Ferguson R, Houghton S: Public support for restrictions on food company sponsorship of community events. Asia Pac J Clin Nutr 2012, 21(4):609-617.

39. Skouteris H, McCabe M, Ricciardelli LA, Milgrom J, Baur LA, Aksan N, Dell'Aquila $D$ : Parent-child interactions and obesity prevention: a systematic review of the literature. Early Child Dev Care 2012, 182(2):153-174.

40. Pinquart M: Associations of general parenting and parent-child relationship with pediatric obesity: a meta-analysis. J Pediatr Psychol 2014, doi:10.1093/jpepsy/jst144

41. Rhee KE: Childhood overweight and the relationship between parent behaviors, parenting style, and family functioning. Ann Am Acad Polit SS 2008, 615:11-37.

42. Yu J: Mothers' perceptions of the negative impact on TV food ads on children's food choices. Appetite 2012, 59:372-376.

43. Beeken RJ, Wardle J: Public beliefs about the causes of obesity and attitudes towards policy initiatives in Great Britain. Public Health Nutr 2013, 16(12):2132-2137.

44. Olds T, Thomas S, Lewis S, Petkov J: Clustering of attitudes towards obesity: a mixed methods study of Australian parents and children. Int J Behav Nutr Phy 2013, 10:117.

45. Kalinowski A, Krause K, Berdejo C, Harrell K, Rosenblum K, Lumeng JC: Beliefs about the role of parenting in feeding and childhood obesity among mothers of lower socioeconomic status. J Nutr Educ Behav 2012, 44(5):432-437

46. Sosa ET: Mexican American mothers' perceptions of childhood obesity: a theory-guided systematic literature review. Health Educ Behav 2012, 39:396-404.

47. Glaser B, Strauss A: The Discovery of Grounded Theory. Chicago: Aldine; 1967

48. Strauss A, Corbin J: Basics of Qualitative Research. Thousand Oaks: Sage; 1990.

49. Phillips JM, Gully SM: Role of goal orientation, ability, need for achievement, and locus of control in the self-efficacy and goal-setting process. J Appl Psychol 1997, 82(5):792-802.

50. Rotter JB: Generalized expectancies for internal versus external control of reinforcement. Psychol Monogr-Gen A 1966, 80(1):1-28.

51. D'Souza G, Rao RC: Can repeating an advertisement more frequently than the competition affect brand preference in a mature market? J Market 1995, 59(2):32-42.

52. Galea S, Tracy M: Participation rates in epidemiologic studies. Ann Epidemiol 2007, 17:643-653.

53. Ustjanauskas AE, Eckman B, Harris UL, Goren A, Schwartz MB, Brownell KD: Focus groups with parents: what do they think about food marketing to their kids? New Haven, CT: Rudd Center for Food Policy and Obesity and Yale University; 2010.

54. Barr-Anderson DJ, Larson NI, Nelson MC, Neumark-Sztainer D, Story M: Does television viewing predict dietary intake five years later in high school students and young adults? Int J Behav Nutr Phy 2009, 6:7.

55. Gomez LF, Parra DC, Lobelo F, Samper B, Moreno J, Jacoby E, Lucumi DI, Matsudo S, Borda C: Television viewing and its association with overweight in Colombian children: results from the 2005 National Nutrition Survey: a cross sectional study. Int J Behav Nutr Phy 2007, 4:41.

56. Australian Bureau of Statistics: Profiles of Health, Australia, 2011-13. Canberra: Australian Bureau of Statistics; 2013. Catalog no. 4338.0.

57. Australian Bureau of Statistics: Australian Health Survey: Physical Activity, 2011-12. Canberra: Australian Bureau of Statistics; 2013. Catalog no. 4364.0.55.004.

58. Dixon H, Scully M, Wakefield M, Kelly B, Chapman K, Donovan R: Parents' responses to nutrient claims and sports celebrity endorsements on energy-dense and nutrient-poor foods: an experimental study. Public Health Nutr 2011, 14(6):1-9. 
59. Chan M: WHO Director-General Addresses Health Promotion Conference. Finland: Opening address at the 8th Global Conference on Health Promotion Helsinki; 2013. 10 June.

60. Moodie R, Stuckler D, Monteiro C, Sheron N, Neal B, Thamarangsi T, Lincoln P, Casswell S, on behalf of The Lancet NCD Action Group: Profits and pandemics: prevention of harmful effects of tobacco, alcohol, and ultra-processed food and drink industries. Lancet 2013, http://www. thelancet.com/journals/lancet/article/PIIS0140-6736\%2812\%2962089-3/fulltext.

61. Marsh DR, Schroeder DG, Dearden KA, Sternin J, Sternin M: The power of positive deviance. Brit Med J 2004, 329:1177-1179.

62. Singhal A: Communicating what works! Applying the positive deviance approach in health communication. Health Commun 2010, 25:605-606.

63. Birch LL, Fisher JO: Development of eating behaviors among children and adolescents. Pediatrics 1998, 101:539-549.

64. Bell AC, Wolfenden $L$, Sutherland $R$, Coggan $L$, Young $K$, Fitzgerald $M$, Hodder R, Orr N, Milat AJ, Wiggers J: Harnessing the power of advertising to prevent childhood obesity. Int J Behav Nutr Phy 2013, 10:114.

65. Klepp K-I, Wind M, de Bourdeaudhuij I, Rodrigo CP, Due P, Bjelland M, Brug $\mathrm{J}$ : Television viewing and exposure to food-related commercials among European school children, associations with fruit and vegetable intake: a cross sectional study. Int J Behav Nutr Phy 2007, 4:46.

doi:10.1186/s40608-014-0017-1

Cite this article as: Pettigrew et al: A conceptual classification of parents' attributions of the role of food advertising in children's diets. BMC Obesity 2014 1:17.

\section{Submit your next manuscript to BioMed Central and take full advantage of:}

- Convenient online submission

- Thorough peer review

- No space constraints or color figure charges

- Immediate publication on acceptance

- Inclusion in PubMed, CAS, Scopus and Google Scholar

- Research which is freely available for redistribution 